\title{
Entrelacs
}

Cinéma et audiovisuel

$14 \mid 2018$

Marchés du film : évolutions, mutations et perspectives

\section{Editorial : Marchés du film : évolutions, mutations et perspectives}

\section{Hélène Laurichesse}

\section{(2) OpenEdition \\ Journals}

Édition électronique

URL : http://journals.openedition.org/entrelacs/4376

DOI : 10.4000 /entrelacs.4376

ISSN : 2261-5482

Éditeur

Éditions Téraèdre

\section{Référence électronique}

Hélène Laurichesse, «Editorial : Marchés du film : évolutions, mutations et perspectives », Entrelacs

[En ligne], 14 | 2018, mis en ligne le 04 janvier 2019, consulté le 22 avril 2019. URL : http://

journals.openedition.org/entrelacs/4376; DOI : 10.4000/entrelacs.4376

Ce document a été généré automatiquement le 22 avril 2019.

Tous droits réservés 


\title{
Editorial : Marchés du film : évolutions, mutations et perspectives
}

\author{
Hélène Laurichesse
}

1 Dans son sens commun, un marché correspond à un rassemblement de personnes, dans un lieu déterminé et dans un but commercial, pour permettre la rencontre entre des acheteurs et des vendeurs. Le marché du film se caractérise alors traditionnellement par un modèle d'intermédiation entre les vendeurs internationaux, les distributeurs et les diffuseurs. Parallèlement, à l'occasion de ces rencontres, le développement de projets et la recherche de financement constituent désormais de véritables enjeux pour les professionnels avec une multiplication des évènements et dispositifs (pitching, atelier, table ronde, conférence) qui atteste du renforcement de cette dimension relationnelle.

2 Le choix du pluriel pour «Les marchés du film» de ce numéro 14 d'Entrelacs traduit la dimension polysémique de cette notion pour en envisager toutes ses dimensions à travers les rôles, les évolutions, les enjeux économiques, financiers, relationnels, et humains de ces places d'échanges.

Cette réflexion vient alimenter des recherches académiques sur les pratiques des professionnels dans l'industrie cinématographique encore très en retrait au regard de celles menées sur les textes, la réception, et les publics. L'éclairage qu'elle apporte permet de revisiter le fonctionnement de cette industrie en pointant notamment la dépendance de l'activité de création à un contexte donné, en l'occurrence celui de l'articulation entre les dynamiques régionales, nationales et transnationales et entre l'artistique et le commercial.

4 Une forte majorité des marchés étudiés dans ce numéro s'adossent à des festivals à Berlin (Ana Vinuela), à Sarajevo (Ana Bento Ribeiro), à Annecy (Jean-Baptiste Scherrer), à Toulouse (Amanda Rueda), à Lille (Timothée Euvrard, Kira Kitsopanidou, Olivier Thevenin) 
Ils peuvent aussi constituer des évènements hors festivals (Le Film Bazaar à Panaji en Inde, Mélanie le Forestier), ou encore mettre en perspective le fonctionnement de la filière audiovisuelle (Clémence Allamand en France, Claude Forest en Afrique sudsaharienne, Samuel Kaczorowski au Japon, Anthony Rescigno en Moselle annexée).

Ces différentes études concernent les dispositifs de mise en relation des professionnels, les rapports de force qui se dessinent entre les différents marchés et ses protagonistes, la nature des transactions qui s'y réalisent, et surtout l'adaptation des marchés du film à la demande d'une industrie en pleine mutation(nouveaux acheteurs, logique de mondialisation et de coproduction, émergence de la réalité virtuelle, logique de concentration du financement des productions).

7 Le témoignage de professionnels (Jérôme Paillard, Directeur du marché du film à Cannes, Pierre Mazars, Dirigeant de la société Charades, spécialisée dans la vente internationale, Aude Hespert, Responsable du département Festival à Unifrance) vient compléter ces approches avec un éclairage sur les grandes tendances à l'œuvre.

8 Comité Scientifique du numéro 14

9 Joël Augros (Professeur à l'Université Bordeaux Montaigne), Lamia Belkaied, (Maître Assistante, École Supérieure de l'Audiovisuel et du Cinéma, Gammarth, Tunisie, Bérénice Bonhomme (MCF à l'Université Toulouse Jean-Jaurès), Benjamin W. L. Derhy Kurtz (Doctorant University of East Anglia, Norwitch UK, Chargé de cours à Paris School of Business, et l'Université Paris 3), Frédéric Gimello-Mesplomb (Professeur à l'Université d'Avignon et des Pays de Vaucluse), Hélène Laurichesse (MCF à l'ENSAV de l'Université Toulouse Jean-Jaurès), Thomas Paris (Professeur affilié HEC, Chargé de recherche au CNRS), Christel Taillibert, (MCF, à l'Université de Nice), Olivier Thevenin, (Professeur à l'Université Paris 3)

\section{AUTEUR}

\section{HÉLÈNE LAURICHESSE}

Hélène Laurichesse est Maître de Conférences à l'ENSAV (École Nationale Supérieure d'Audiovisuel) de l'Université Toulouse-Jean-Jaurès et chercheuse au LARA-SEPPIA. Ses recherches portent sur le fonctionnement de l'industrie cinématographique à travers les pratiques des différents acteurs de la filière (auteurs, réalisateurs, producteurs, distributeurs, exploitants) et les stratégies qui s'y déploient. 